\section{Preparation of a}

Monolith-Supported

$\mathrm{Au} / \mathrm{TiO}_{2}$ Catalyst

Active for $\mathrm{CO}$

Oxidation

\section{François Moreau ${ }^{1}$, Geoffrey C Bond ${ }^{1 *}$, Ronald Hughes ${ }^{1}$, Jacob A Moulijn ${ }^{2}$, Michiel Makkee ${ }^{2}$, Kamasamudram Krishna², and Bozena Aeijelts Averink Silberova ${ }^{2}$}

${ }^{1}$ Institute for Materials Research, University of Salford, Salford, Greater Manchester M5 4WT, UK

${ }^{2}$ DelftChem Tech, Catalysis Engineering, Faculty of Applied Sciences, Delft University of Technology, Julianlaan 136, NL 2628 BL, The Netherlands

* Corresponding author, e-mail address Geoffrey10bond@aol.com

\begin{abstract}
The development of a method for making an adherent coating of $\mathrm{Au} / \mathrm{TiO}_{2}$ on a cordierite monolith is described. The optimum method entails first forming a wash-coat of $\mathrm{TiO}_{2}$ by combining a colloidal dispersion of $\mathrm{TiO}_{2}$ with Degussa P-25 $\mathrm{TiO}_{2}$ that has been washed, dried and crushed. Subsequent deposition of gold from $\mathrm{HAuCl}_{4}$ solution at $\mathrm{pH} 9$ resulted in a catalyst that was less active for the oxidation of carbon monoxide than a similar preparation using only P-25, but reproducible values of $\mathrm{T}_{50}$ of about $250 \mathrm{~K}$ were obtained.
\end{abstract}

\section{Keywords}

cordierite monolith, gold on titania, CO oxidation

\section{Introduction}

The discovery that supported gold catalysts can have high activity for the oxidation of $\mathrm{CO}$ has stimulated extensive research on them [1]. It is now evident that this activity is directly linked to two main factors: (i) small particle size, and (ii) the use as support of an oxide of a transition metal able to assist the reaction [2,3]. The most widely-used preparative method is the so-called deposition-precipitation, first employed by M. Haruta and his associates [4]; careful control of the $\mathrm{pH}$ especially during the final stages of the preparation has enabled the activity of $\mathrm{Au} / \mathrm{TiO}_{2}$ catalysts to be maximised [5].

The largest application of ceramic monoliths as catalyst supports is in the automotive industry, for the control of gaseous and particulate emissions from gasoline and dieselfuelled engines; all automobiles are now fitted with either ceramic or metallic honeycomb-supported catalysts, which have now replaced packed-bed reactors [6]. The channels permeating the monolith allow high flow-rates with only a low pressure-drop. Cordierite $\left(\mathrm{Al}_{3} \mathrm{Mg}_{2} \mathrm{Si}_{5} \mathrm{AlO}_{18}\right)$, selected because of its commercial availability, has a low thermal expansion coefficient, high mechanical strength and excellent thermal stability, and is therefore often used as a material for monoliths. Its main disadvantage is its low surface area $(0.7$ $\mathrm{m}^{2} \mathrm{~g}^{-1}$ ), but this can be increased by deposition of a 'wash coat' of a high-area oxide. Typically alumina is introduced inside the channels by a 'dip and drain' technique; the coated monolith is then calcined. The noble metals platinum and palladium, which are able to resist high temperature and are relatively sulfur tolerant, can be impregnated as their salts during a second stage or directly added in the washcoat to impart the necessary catalytic activity [7]. Gold catalysts, suitably prepared, have a much higher activity for CO oxidation than either palladium or platinum [4], and its ability to resist sulphur poisoning has been briefly discussed [1]. Gold could therefore be of potential interest for the control of gaseous emissions.

The preparation and testing of monolithic catalysts is of interest to many research groups [7-10]. Many different techniques for putting a wash-coat on the monolithic body have been used; for example, colloid, sol-gel, slurry and polymer coating [7]. Lee and Gavriilidis [11] have reported a high catalytic activity for $\mathrm{Au} / \gamma-\mathrm{Al}_{2} \mathrm{O}_{3} /$ cordierite monoliths for $\mathrm{CO}$ oxidation, although alumina is not generally recognised as being the first choice of support for gold catalysts [1]; their work will be considered further below.

The purpose of the present work was to develop a procedure for coating pieces of cordierite monolith with an $\mathrm{Au} / \mathrm{TiO}_{2}$ catalyst that would be active for the oxidation of CO. We previously listed some of the variables in the preparation of powder $\mathrm{Au} / \mathrm{TiO}_{2}(\mathrm{P}-25)$ catalysts, any of which could affect their performance in CO oxidation [5,12,13], and we reported in particular on the influence on $\mathrm{pH}$ control in determining the gold particle size and activity. Those different studies have been used in order to propose a suitable 
method of preparation of Au/monolith catalyst active for CO oxidation.

\section{Experimental Procedures, Preparation Methods, Results and Discussion}

It is convenient to present the results obtained by each method used immediately after its description. The procedure for the catalytic testing is therefore described first; certain of the monolith preparations used a pre-formed $\mathrm{Au} / \mathrm{TiO}_{2}$ catalyst [5], the preparation of which is then outlined.

\section{Oxidation of Carbon Monoxide}

This was carried out in a plug-flow reactor, the gas flow (0.50 vol\% CO) in synthetic air being introduced through a mass flow controller [5]. The standard test used a $55 \mathrm{~cm}^{3} \mathrm{~min}^{-1}$ reactant flow and $50 \mathrm{mg}$ of catalyst powder (space velocity $\left.17,000 \mathrm{~h}^{-1}\right)$. Analysis was performed on-line by means of a Varian 3300 CC using a manual sampling valve, CTRI column (Alltech), TCD, and helium carrier gas. The experiments were carried out between 183-373 K, sub-ambient temperatures being achieved by mixing methanol with Cardice or liquid nitrogen; higher temperatures were obtained by heating the reactor in a furnace. CO conversion was measured as a function of temperature. Activity was first tested at room temperature after three hours, the reactor was then placed in a Dewar flask, and the temperature lowered, after which it was allowed to rise stepwise. Various pieces of treated monolith were tested under the same conditions (see Table 1); each piece was wrapped in Teflon tape to minimise gas flow between it and the reactor wall. The test used a $55 \mathrm{~cm}^{3}$ $\mathrm{min}^{-1}$ reactant flow and 160 - 530 mg monolith pieces (space velocity $3,700-12,250 \mathrm{~h}^{-1}$ ).

Preparation of $1 \%$ Au/TiO 2 (Degussa P-25) powder catalyst Deposition-precipitation (DP) is a seemingly simple procedure of catalyst preparation, capable however of numerous variations, some of which have been described in the literature [1], but all too often the published accounts omit details that might be important or even critical. We have previously listed some of the variables in the preparation of $\mathrm{Au} / \mathrm{TiO}_{2}(\mathrm{P}-25)$ catalysts, any of which could affect their performance in CO oxidation $[5,12,13]$, and have reported in particular on the influence on $\mathrm{pH}$ control in determining the gold particle size and activity with gold loadings of less than $2 \%$. A procedure was formulated in which the optimum $\mathrm{pH}$ for high activity was shown to be $\sim 9$.

A reference powder catalyst was prepared by this method: the $\mathrm{pH}$ of an aqueous $\mathrm{HAuCl}_{4}$ solution $\left(10^{-4} \mathrm{M}\right)$ was first raised to 10 using $0.1 \mathrm{M} \mathrm{NaOH}$ solution. $\mathrm{TiO}_{2}$ (1g per $50 \mathrm{ml}$ solution, Degussa P-25, as received) was then added with stirring at room temperature; there was an immediate decrease in $\mathrm{pH}$, which was then raised and held at 9 by further addition of $0.1 \mathrm{M} \mathrm{NaOH}$ as necessary. The resulting suspension was stirred for 1 hour at $343 \mathrm{~K}$. After cooling it was filtered and the solid washed thoroughly and then vacuum-dried at room temperature. The catalyst was not calcined. The actual gold content was determined by Atomic Absorption Spectroscopy [5].

\section{Preparation of coated monoliths}

The cordierite monolith pieces supplied by Corning were cylindrical, $4 \mathrm{~cm}$ long and $0.6 \mathrm{~cm}$ diameter; the wall thickness was $\sim 0.16 \mathrm{~mm}$, and the cell dimension corresponded to 62 cells $\mathrm{cm}^{-2}$, (i.e. $400 \mathrm{cpsi}$ ). Each piece weighed about $0.5 \mathrm{~g}$.

In order to ensure adherence of the catalyst or its support to the walls of the monolith's channels, a colloidal dispersion of the supporting oxide is commonly used as a binder [6]. A $\mathrm{TiO}_{2}$ colloid was therefore first prepared by slowly adding 0.3 mole of $\mathrm{Ti}\left(\mathrm{O}-{ }^{\mathrm{i}} \mathrm{C}_{3} \mathrm{H}_{7}\right)_{4}$ to 1 I of distilled water at $343 \mathrm{~K}$; the speed of addition was $1 \mathrm{ml} \mathrm{min-1}$. The alkoxide was hydrolysed by adding 0.15 mole of $\mathrm{HNO}_{3}$ dropwise, and the hydrolysis was continued at $353 \mathrm{~K}$ for $16 \mathrm{~h}$ with vigorous stirring; the final $\mathrm{pH}$ of the suspension was 1.6.

\section{Scanning electron microscopy}

The surface morphology of the coated monoliths was studied using a Phillips XL20 Scanning Electron Microscope; the samples were first sputtered with a thin layer of gold to avoid charging.

\section{First method}

As it is important to limit the number of steps in a catalyst preparation, a procedure known as 'slurry coating' was first attempted using the pre-formed $\mathrm{Au} / \mathrm{TiO}_{2}$, to avoid having to carry out a further impregnation to introduce the metal. The $\mathrm{Au} / \mathrm{TiO}_{2}$ was added to the colloid, and as large particles of the catalyst were then present with the much smaller $\left(x 10^{2}\right)$ colloidal particles of $\mathrm{TiO}_{2}$, the slurry was ball-milled (Fritsch type 00.001, model 523) to lower the size of the catalyst particles below $5 \mu \mathrm{m}$, so that they were comparable to the size of the larger macropores of the cordierite. They were therefore able to enter these pores, and therefore a stronger binding of the catalyst was obtained. The monolith was first dried at $393 \mathrm{~K}$ for $24 \mathrm{~h}$, and after cooling it was placed in the slurry for $2 \mathrm{~min}$; it was then withdrawn, shaken to remove the excess slurry and warm air was blown into the channels from sequentially altered directions to clear the channels further. It was then placed in an oven, the temperature of which was raised $\left(0.2 \mathrm{~K} \mathrm{~min}^{-1}\right)$ to $393 \mathrm{~K}$, where it remained for $24 \mathrm{~h}$.

Despite the good quality of the coating, the monolith failed to exhibit any activity for $\mathrm{CO}$ oxidation below $423 \mathrm{~K}$, the main reason being that the final $\mathrm{pH}$ of the preparation (1.5) was too low; previous work [12] has shown that at this $\mathrm{pH}$ previously formed gold particles can dissolve and be redeposited as precursors to much larger particles.

\section{Second method}

In order to avoid this problem, the $\mathrm{pH}$ of the $\mathrm{TiO}_{2}$ colloid was first raised to 9 by adding $0.1 \mathrm{M} \mathrm{NaOH}$, but this caused it to coagulate; nevertheless the catalyst was added, and the 
Table 1

Activity of $\mathrm{Au} / \mathrm{TiO}_{2}$ supported on cordierite monolith prepared by method 4 for oxidation of $\mathrm{CO}$

\begin{tabular}{ccccc}
$\begin{array}{c}\text { Wt. } \\
\text { Catalyst/g }\end{array}$ & $\begin{array}{c}\text { Wt. } \\
\mathrm{Au} / \mathrm{mg}\end{array}$ & $\mathbf{T}_{50} / \mathbf{K}$ & $\mathbf{r}_{\mathrm{sp}}{ }^{\mathrm{a}}$ & $\begin{array}{c}\mathrm{E}_{\mathrm{a}} / \mathrm{kJ} \\
\mathrm{mol}^{-1}\end{array}$ \\
\hline 0.53 & 1.8 & 265 & 0.1 & 25 \\
0.50 & 2.75 & 255 & 0.35 & 22 \\
0.16 & 1.1 & 259 & 0.4 & 35 \\
0.30 & 2.1 & 245 & 0.4 & 35 \\
\hline
\end{tabular}

${ }^{a}$ In mol $\mathrm{CO}^{-1} \mathrm{~g}_{\mathrm{Au}}^{-1}$ at $243 \mathrm{~K}$

monolith dipped in the resulting slurry: no ball-milling was performed. There was some increase in catalytic activity, but the coagulation caused the coating to be thick and irregular. This method was deemed unsatisfactory.

\section{Third method}

An attempt was then made to deposit a freshly prepared Au/ $\mathrm{TiO}_{2}$ catalyst onto the monolith without the assistance of the $\mathrm{TiO}_{2}$ colloid. The catalyst powder was carefully milled and then mixed with deionised water; the slurry was ball-milled, and the $\mathrm{pH}$ raised to 9 by $\mathrm{NaOH}$ addition. The monolith was dipped into this, and processed as before. Although it showed activity for CO oxidation, visual inspection showed that the quality of the coating was not satisfactory, and a properly attached layer could not be obtained in the absence of the colloid.

\section{Fourth method}

It was then decided to resort to first forming a $\mathrm{TiO}_{2}$ coating on the monolith, and then depositing gold on it from $\mathrm{HAuCl}_{4}$ solution. In a first attempt the monolith was dipped into a slurry of P-25 $\mathrm{TiO}_{2}\left(10 \mathrm{~g}\right.$ ) with the $\mathrm{TiO}_{2}$ colloid (50 g) without ball-milling, but after processing it was seen that a very poor coating had been produced. It was then discovered that first washing, drying and crushing the P-25 before combining it with the colloid led to a good quality coating, on which the gold could then be deposited. $1 \mathrm{~g}$ of $\mathrm{TiO}_{2} \mathrm{P}-25$ was suspended in $50 \mathrm{ml}$ deionised water and stirred for $1 \mathrm{~h}$ at $343 \mathrm{~K}$; it was then filtered, washed thoroughly and vacuum-dried at $373 \mathrm{~K}$. $10 \mathrm{~g}$ of the washed and dried $\mathrm{TiO}_{2}$ was crushed before being added to $50 \mathrm{~g}$ of the $\mathrm{TiO}_{2}$ colloid, and the suspension vigorously stirred; it was then used to coat the monolith by the method described above.

The coated monolith pieces were held in place in a beaker by means of plastic-coated wires that kept them along the wall at the bottom of the beaker, and then immersed in a solution of $\mathrm{HAuCl}_{4}$ raised to $\mathrm{pH} 9$ by $\mathrm{NaOH}$. This solution was then agitated by a magnetic stirrer in order to ensure passage of the solution through the channels of the monolith, the direction of flow through the channels being changed periodically to obtain a better distribution of metal along their length. After draining, and drying at 373
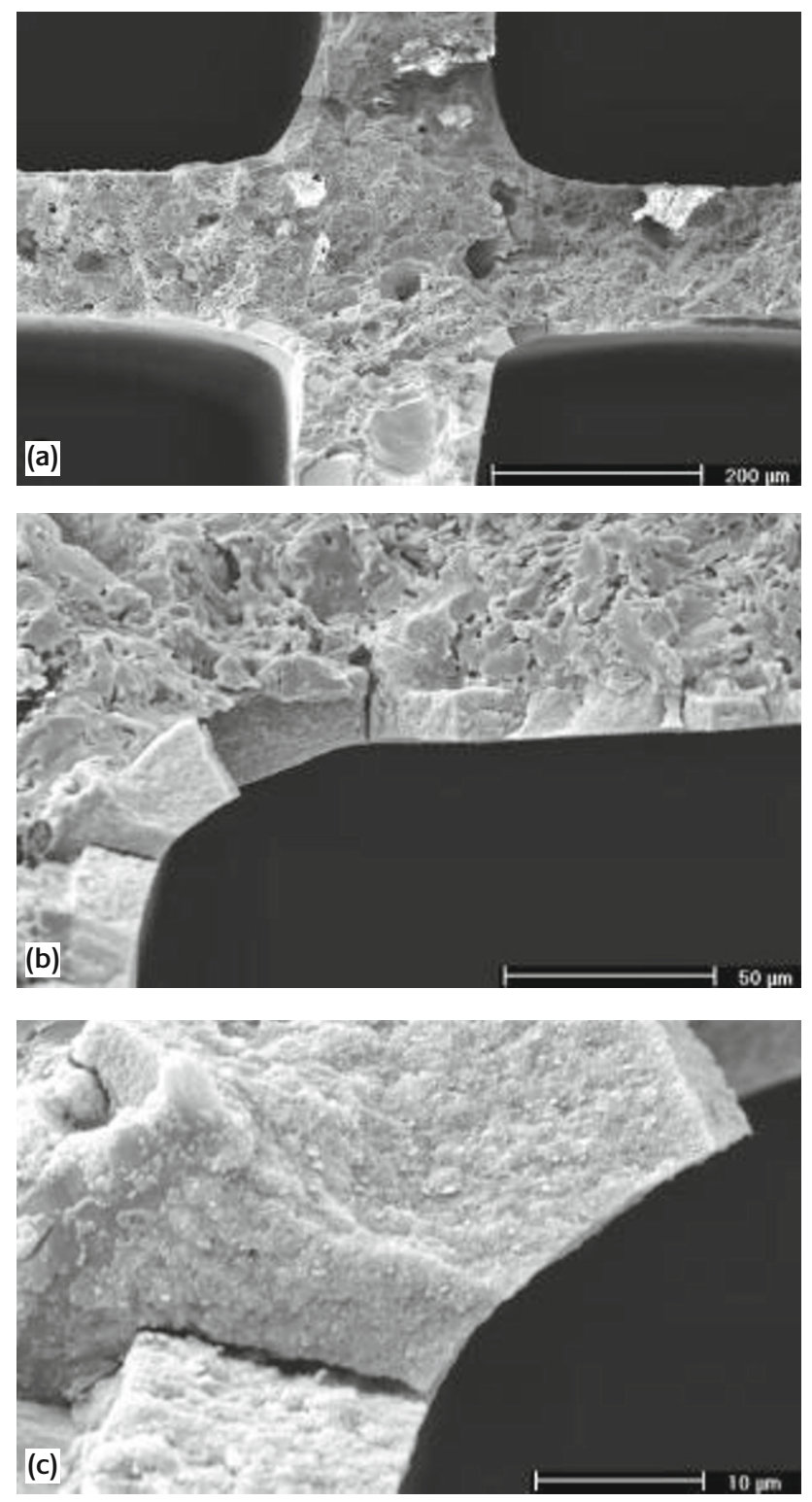

Figure 1

Scanning electron micrographs of the Au/TiO ${ }_{2}$ monolith catalysts prepared by the fourth method

$\mathrm{K}$, the monolith was tested for $\mathrm{CO}$ oxidation, and a much higher activity was found. Four monolith pieces were prepared in an identical manner, and showed excellent reproducibility (see Table 1). A long-term test was performed at room temperature on one of the monoliths, and after a slight decrease in conversion during the first $25 \mathrm{~h}(0.15 \%$ conversion $\mathrm{h}^{-1}$ ), the catalyst was quasi-stable during the following $50 \mathrm{~h}$ (Figure 2).

In order to see whether the activity shown by the monolith was affected by the process of forming the coating and by the way in which the gold was deposited, the material formed by drying the slurry of the washed P-25 plus the colloid was used as support in a conventional preparation. This was carried out by depositing a gold precursor at $\mathrm{pH} 9$ and room temperature.

The gold content was only $0.34 \%$, but the resulting catalytic activity $\left(0.4 \times 10^{-4} \mathrm{~mol}_{\mathrm{CO}} \mathrm{s}^{-1} \mathrm{~g}_{\mathrm{Au}}^{-1}\right.$ at $\left.243 \mathrm{~K}\right)$ was the same as that shown by the best monolith pieces 


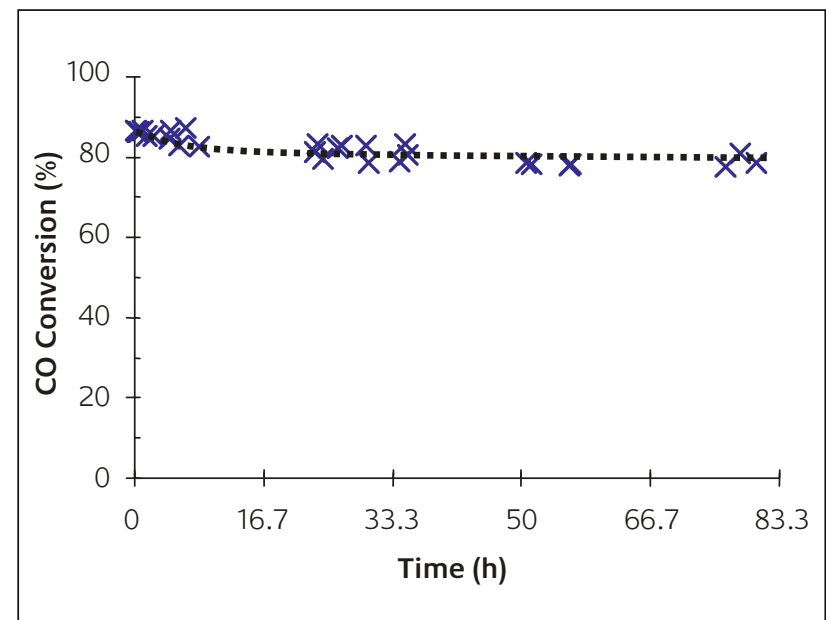

Figure 2

Long term stability test at room temperature on an Au/monolith sample; (190 mg catalyst, $55 \mathrm{ml} \mathrm{min}{ }^{-1} 0.5 \mathrm{vol}$ \% CO (balance air))

(see Table 1); this was however somewhat smaller than that shown by a $0.5 \% \mathrm{Au} / \mathrm{TiO}_{2}$ catalyst $\left(3.7 \times 10^{-4} \mathrm{~mol}_{\mathrm{CO}} \mathrm{s}^{-1} \mathrm{~g}_{\mathrm{Au}}{ }^{-1}\right.$ at $243 \mathrm{~K}$ ). A possible reason for this is that some of the metal may have been encapsulated by the colloid during the preparation.

\section{Examination of coated monoliths by SEM}

Extensive examination of the products of each method of preparation was conducted by scanning electron microscopy (SEM), and the qualitative observations on the degree of success reported above are based on this technique. Using monoliths made by the fourth method, SEM images were obtained of the top of the monolith, on a cut about $5 \mathrm{~mm}$ below the top, and on a cut made at about the middle. Perpendicular views of the coated layer in inner and outer channels as well as cross-sections of the coating were taken. The presence of coating material inside the cordierite structure was also probed.

The monolith was seen to be almost homogeneously coated by $\mathrm{TiO}_{2}$; the thickness of the layer varied slightly from channel to channel, and along the length of the channel. On the top and bottom the coated layer was slightly thicker than in the middle. The average thickness near the middle was about $20 \mu \mathrm{m}$ in the corners of the channels, and about 10 $\mu \mathrm{m}$ along the walls, this causing the channels to become more circular in appearance. The coating consisted of particles of less than $1 \mu \mathrm{m}$ in size. Figures 1 to 3 illustrate the quality of the coating as it existed $5 \mathrm{~mm}$ from the top of the piece.

\section{Comparison with other work}

Lee and Gavriilidis [11] have applied an aqueous solution of $\mathrm{HAuCl}_{4}$ held at $\mathrm{pH} 9$ for $4 \mathrm{~h}$ to a cordierite monolith already coated with $\gamma-\mathrm{Al}_{2} \mathrm{O}_{3}$; after hot-water washing and drying in air at $393 \mathrm{~K}$, it was calcined at $573 \mathrm{~K}$ for $4 \mathrm{~h}$. It weighed $1.5 \mathrm{~g}$ and its gold loading was $0.082 \%$; using $1 \% \mathrm{CO}$ and a

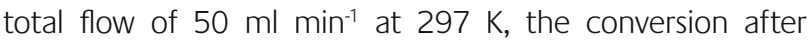
150 min was $\sim 85 \%$. This corresponds to a rate of about
$0.1 \mathrm{~mol}_{\mathrm{CO}} \mathrm{s}^{-1} \mathrm{~g}_{\mathrm{Au}}^{-1}$, but quantitative comparison with our activities is impossible due to the large difference in temperature.

\section{Conclusions}

Construction of a coherent uniform wash-coat of $\mathrm{TiO}_{2}$ on cordierite monolith appears to depend critically on the use of a $\mathrm{TiO}_{2}$ colloidal binder, and on prior washing of the P-25 before its admixture with the colloid. It is unclear what the physical consequences of the washing, drying and crushing the P-25 are; this will require further work.

The specific activity of the $\mathrm{Au} / \mathrm{TiO}_{2}$ on the monolith, and of the powder form of the catalyst containing the colloid, was somewhat less active than a typical $1 \% \mathrm{Au} / \mathrm{TiO}_{2}$ catalyst, but optimisation of the parameters of the preparation should enable this difference to be removed.

\section{About the corresponding author}

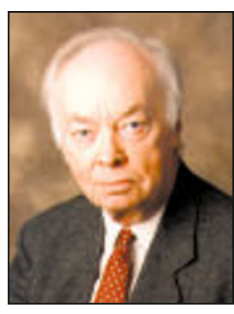

Geoffrey Bond held academic posts at the Universities of Leeds and Hull before joining Johnson Matthey plc as Head of Catalysis Research in 1962. In 1970 he was appointed Professor of Applied Chemistry at Brunel University; he retired in 1992 and is now Emeritus Professor.

\section{Acknowledgement}

We gratefully acknowledge financial support from the European Commission's FP5 programme through the AURICAT Training Network HPRN-CT-2002-00174.

\section{References}

1 G.C. Bond, C. Louis, D.T. Thompson, Catalysis by Gold, IC Press, London, 2006

2 G.C. Bond, D.T. Thompson, Catal. Rev. - Sci. Eng. 41 (1999) 319

3 G.C. Bond, D.T. Thompson, Gold Bull. 33 (2000) 41

4 M. Haruta, T. Kobayashi, H. Sans, Y. Yamada, Chem. Lett. (1987) 405

5 F. Moreau, G.C. Bond, A.O. Taylor, J. Catal. 231 (2005) 105

6 F. Kapteijn, J.J. Heiszwolf, T.A. Nijhuis, J.A. Moulijn, Cattech 5 (1999) 24

7 T.A. Nijhuis, A.E.W. Beers, T. Vergunst, I. Hoek, F. Kapteijn, J.A. Moulijn, Catal. Rev.- Sci. Eng. 43 (2001) 345

8 A.F. Pérez-Cadenas, M.M.P.Zieverink. F. Kapteijn, J.A. Moulijn, Catal. Today 105 (2005) 623

9 A.S. Bodke, D.A. Olschki, L.D. Schmidt, E. Ranzi, Science 285 (1999) 712

10 R.M. Heck, S. Gulati, R.J. Farrauto, Chem. Eng. J. 82 (2001) 149

11 Seng-Jae Lee, A. Gavriilidis, J. Catal. 206 (2002) 305

12 F. Moreau, G.C. Bond, Appl. Catal. A: Gen. 302 (2006) 110

13 F. Moreau, G.C. Bond, and A.O. Taylor, Chem. Commun. (2004) 1642 